\title{
Resource-saving techniques for increasing tomato productivity
}

\author{
Elena V. Kalmykova ${ }^{1 *}$, Aleksey A. Novikov ${ }^{1}$, \\ Nikolay Yu. Petrov², Olga V. Kalmykova ${ }^{2}$ \\ ${ }^{1}$ Russian Research Institute of Irrigated Agriculture \\ Volgograd, Russian Federation \\ ${ }^{2}$ Volgograd State Agrarian University \\ Volgograd, Russian Federation \\ *Correspondent author: kalmykova.elena-1111@yandex.ru
}

\begin{abstract}
The purpose of the research was to substantiate feasibility and effectiveness of cultivating promising tomatoes varieties and hybrids in the Lower Volga region to obtain high-quality yields of $150 \mathrm{t} / \mathrm{ha}$ and more. It was the first time for chestnut soils, when comprehensive research on resource-saving techniques increasing vegetable crop productivity in an extremely arid climate under drip irrigation by regulating physiological and biological processes was conducted, and a system for applying these techniques was developed. The experiments were carried out according to generally accepted methods. The study revealed that in order to obtain the planned productivity of $110,130,150 \mathrm{t} / \mathrm{ha}$ in all the tomato varieties and a hybrid (Volgogradsky 5/95, Fokker F1 and Gerkules), differentiated irrigation regime was used. It resulted in yield increase up to $18.8 \mathrm{t} / \mathrm{ha}$ (when compared to planned $130 \mathrm{t} / \mathrm{ha}$ ) and up to $10.2 \mathrm{t} / \mathrm{ha}$ (when compared to planned $150 \mathrm{t} / \mathrm{ha}$ ) in the variants where Energiya-M growth regulator and Rastvorin water-soluble fertilizer were used with complete mineral fertilizer. Hercules tomato variety treated with $\mathrm{N}_{285} \mathrm{P}_{115} \mathrm{~K}_{145}+$ Rastvorin + Energiya-M was the most economically viable for cultivation. According to the variants, a return on production costs of 6.87 rubles of income was achieved.
\end{abstract}

Key words: irrigation regime, productivity, tomato, water-soluble fertilizers, growth regulator, quality improvement

\section{Article history:}

Received: 9 September 2019. Accepted: 14 November 2019

\section{For citation:}

Kalmykova EV, Novikov AA, Petrov NY, Kalmykova OV. Resource-saving techniques for increasing tomato productivity. RUDN Journal of Agronomy and Animal Industries. 2019; 14(4): 329-346. doi: 10.22363/2312-797X-2019-14-4-329-346

(C) Калмыкова Е.В., Новиков А.А., Петров Н.Ю., Калмыкова О.В., 2019.

(C) This work is licensed under a Creative Commons Attribution 4.0 International License https://creativecommons.org/licenses/by/4.0/ 


\title{
Комплексные научные исследования ресурсосберегающих приемов повышения продуктивности томата
}

\author{
Е.В. Калмыкова ${ }^{1 *}$, А.А. Новиков ${ }^{1}$, \\ Н.Ю. Петров ${ }^{2}$, О.В. Калмыкова \\ ${ }^{1}$ Всероссийский научно-исследовательский институт орошаемого земледелия, \\ 2. Волгоград, Российская Федерация \\ ${ }^{2}$ Волгоградский государственный аграрный университет, \\ 2. Волгоград, Российская Федераиия \\ *kalmykova.elena-1111@yandex.ru
}

\begin{abstract}
Аннотация. Цель исследований - обосновать целесообразность и эффективность возделывания перспективных сортов и гибридов томатов в условиях Нижнего Поволжья для получения урожайности 150 и более т/га высококачественной продукции. Впервые в зоне каштановых почв проводились комплексные научные исследования ресурсосберегающих приемов повышения продуктивности овощной культуры в условиях острозасушливого климата путем регулирования физиолого-биологических процессов при капельном орошении и разработана система применения этих приемов. Исследования в опыте осуществлялись согласно общепринятым методикам. По результатам исследований было выявлено, что на культуре томат, на всех исследуемых сортах и гибриде (Волгоградский 5/95, Фоккер $\mathrm{F}_{1}$ и Геркулес), для получения планируемой продуктивности в $110,130,150$ т/га необходимо создавать дифференцированный режим орошения, что давало возможность получать прибавку урожайности до 18,8 т/га (на планируемую урожайность 130 т/га) и до 10,2 т/га (на планируемую урожайность 150 т/га) в вариантах NPK + Растворин + Энергия-М. Для производителя наиболее экономически оправданным являлось возделывание томата сорта Геркулес на фоне $\mathrm{N}_{285} \mathrm{P}_{15} \mathrm{~K}_{145}+$ Растворин + Энергия-М. По вариантам достигалась окупаемость производственных затрат в сумме 6,87 рублей дохода.
\end{abstract}

Ключевые слова: режим орошения, продуктивность, томат, водорастворимые удобрения, регулятор роста, повышение качества

\section{История статьи:}

Поступила в редакцию: 9 сентября 2019 г. Принята к публикации: 14 ноября 2019 г.

\section{Для цитирования:}

Калмыкова Е.В., Новиков А.А., Петров Н.Ю., Калмыкова О.В. Комплексные научные исследования ресурсосберегающих приемов повышения продуктивности томата // Вестник Российского университета дружбы народов. Серия: Агрономия и животноводство. 2019. Т. 14. № 4. 329-346. doi: 10.22363/2312-797X-2019-14-4-329-346

\section{Introduction}

Vegetable growing is one of the main branches in agro-industrial complex, providing population with vitamins $\mathrm{C}, \mathrm{B}, \mathrm{B}_{2}, \mathrm{~A}, \mathrm{H}, \mathrm{B}_{9}$, pectin, minerals, nutrients and other substances that determine a person's healthy diet all year round [1-3].

In the Russian Federation, main vegetable croplands including tomatoes are located in the southern regions. The Lower Volga region is considered to be 'Russian garden'. 
The region has favorable climatic conditions for vegetable growing and, therefore, occupies a leading position in the country in vegetables production. Here, the industry depends on irrigation, since irrigated agriculture occupying 53\% of the arable land gives $90 \%$ of all gross output [4]. Vegetable production in this region is at consistently high levels - open-ground vegetable harvests in the industrial sector of vegetable growing amounted to 531.3 thousand tons in 2016 - 11.6\% of the total value in the Russian Federation, this was the second place among Russian regions. For sown areas, the second place belongs to vegetable crops - 15.6 thousand ha, which is $8.3 \%$ of all areas [5].

Tomatoes are one of the most nutritious vegetables. The fruits of tomatoes contain sugars, acids, aromatic substances, as well as a large amount of vitamins. High taste, nutritional and dietary qualities, and a variety of cooking methods have made tomatoes a popular vegetable $[3,6]$.

Currently, production of open ground vegetables is carried out mainly without drip irrigation, not considering variety adaptability to climatic conditions [7-9].

High yields combined with high quality fruits are a common requirement for tomato producers, which can only be achieved considering critical production factors. These include proper irrigation management, variety selection, disease prevention, soil fertility, climate, etc. Many authors have revealed that adherence to agro-technological measures with the key role of nutrition determined tomato quality and yield [10 - 17].

Therefore, the study on resource-saving techniques increasing vegetable crop yields, including micro-irrigation, water-soluble fertilizers and growth stimulants, is relevant.

The purpose of the research was to rationalize technological methods for obtaining $150 \mathrm{t} / \mathrm{ha}$ and more high-quality yields of vegetables considering climatic conditions of the Lower Volga region.

\section{Materials and methods}

Split plot experiments were carried out according to [18-21]. Arrangement of plots by varieties and hybrids was systematic, by nutritional regimes — randomized. The accounting area of first-order plots (water regime), second-order plots (varieties and hybrids) and third-order plots (nutrient regimes) was $295 \mathrm{~m}^{2}, 100 \mathrm{~m}^{2}$ and $7.5 \mathrm{~m}^{2}$, respectively. The experiment was replicated three times. Scheme for sowing tomato seeds was $0.50+0.90 \mathrm{~m}$.

Factor $A$ - agro-ecological assessment of varieties and hybrids of Russian and foreign breeding. The following tomato varieties and hybrids were studied: Volgogradsky 5/95 (standard), Fokker F1 hybrid, Gerkules variety.

Factor $B$ - scientific substantiation of managing planned tomato productivity: 110, 130, $150 \mathrm{t} / \mathrm{ha}$. Variants:

1) control;

2) Energiya-M growth regulator;

3) fertilizers for $110 \mathrm{t} /$ ha yield: $\mathrm{N}-210 \mathrm{~kg} /$ ha active ingredient; $\mathrm{P}_{2} \mathrm{O}_{5}-85 \mathrm{~kg} / \mathrm{ha}$ active ingredient, $\mathrm{K}_{2} \mathrm{O}-105 \mathrm{~kg} / \mathrm{ha}$ active ingredient;

4) fertilizers for $130 \mathrm{t} /$ ha yield: $\mathrm{N}-250 \mathrm{~kg} /$ ha active ingredient; $\mathrm{P}_{2} \mathrm{O}_{5}-100 \mathrm{~kg} / \mathrm{ha}$ active ingredient; $\mathrm{K}_{2} \mathrm{O}-125 \mathrm{~kg} /$ ha active ingredient; 
5) fertilizers for $150 \mathrm{t} / \mathrm{ha}$ yield: $\mathrm{N}-285 \mathrm{~kg} /$ ha active ingredient; $\mathrm{P}_{2} \mathrm{O}_{5}-115 \mathrm{~kg} / \mathrm{ha}$ active ingredient, $\mathrm{K}_{2} \mathrm{O}-145 \mathrm{~kg} /$ ha active ingredient;

6) Rastvorin water-soluble fertilizer;

7) Rastvorin water-soluble fertilizer and Energiya-M growth regulator;

8) NPK fertilizers, Rastvorin and Energiya-M for 110 t/ha yield;

9) NPK fertilizers, Rastvorin and Energiya-M for 130 t/ha yield;

10) NPK fertilizers, Rastvorin and Energiya-M for $150 \mathrm{t} /$ ha yield.

Factor $C$ - irrigation regimes affect on tomato productivity:

1) maintaining pre-irrigation moisture level at $75 \ldots 75 \ldots 75 \%$ field capacity (FC) (constant irrigation regime);

2) maintaining pre-irrigation moisture level at $70 \ldots 80 \ldots 75 \% \mathrm{FC}$ (differentiated irrigation regime): sowing - flowering - 70\% FC; flowering — milk ripeness $80 \% \mathrm{FC}$; milk ripeness - full ripeness - 75\% $\mathrm{FC}$.

As mineral fertilizers, ammonium nitrate, double superphosphate and potassium chloride were studied. For irrigation in the experimental plot, Neodrip drip irrigation system was mounted complete with drip pipelines having water outlets every $0.3 \mathrm{~m}$ and $1.55 \mathrm{l} / \mathrm{h}$ dropper capacity. Irrigation pipelines of drip irrigation system were laid simultaneously during crop sowing.

The first top dressing (10..15 g of Rastvorin per 101 of water) was carried out after 5...7 leaves appeared. During fruit formation, Rastvorin solution (25 g per 101 of water) was used. Spraying was carried out with the same solution after $7 \ldots 10$ days. The presence of several fertilizers made it possible to combine top dressing depending on phase of plant development. The treatment with Energiya-M growth regulator included: 1) seed soaking (1 ml/1 kg of seeds) for $30 . .40 \mathrm{~min}$ with operation solution flow rate of $21 / \mathrm{kg}$; 2) subsequent spraying (15 g/ha) and leaf top dressing (15 g per $300 \mathrm{~g}$ of water) in initial growth period, and during flower formation-flowering growth stage.

\section{Results and Discussion}

The studies were conducted in 2011-2016 in Zaitseva V.A. farm, Gorodishchensky district, the Volgograd region. Composition of the studied soils was heavy loamy in $80 \%$ of the territory and was characterized by a low (2.31\%) humus content in arable layer, and at a depth of $0.4 \ldots 1.0 \mathrm{~m}$ its amount decreased from 1.05 to $0.32 \%$. Low humus content in this soil is explained by the fact that conversion of organic substances in the zone of chestnut soils has a specific zonal character. Water-physical soil properties are affected directly by soil composition. Soil density varied horizontally, the lowest was noted in $0.0 \ldots 0.1 \mathrm{~m}$ layer $-1.24 \mathrm{t} / \mathrm{m}^{3}$. With further deepening, this indicator increased in the studied soil layer: for $0.0 \ldots 0.6 \mathrm{~m}$ - to $1.35 \mathrm{t} / \mathrm{m}^{3}$, for $0.0 \ldots 1.0 \mathrm{~m}$ - to $1.45 \mathrm{t} / \mathrm{m}^{3}$. The highest soil density was noted at $1 \mathrm{~m}$ depth and amounted to $1.62 \mathrm{t} / \mathrm{m}^{3}$. Total soil porosity of arable layer ranged from 50.4 to $47.5 \%$. The field capacity ranged from $25.60 \%$ in $0.0 \ldots 0.1 \mathrm{~m}$ layer to $22.82 \%$ in $0.0 \ldots 0.6 \mathrm{~m}$ layer. The field capacity was $20.4 \%$, wilting moisture for $0.0 \ldots 1.0 \mathrm{~m}$ layer averaged $8.49 \%$; soil $\mathrm{pH}$ was $6.8 . .8 .0$. Hydrolyzable nitrogen availability (according to Kornfield [22 -23]) of experimental plot soil was low (less than $100 \mathrm{mg} / \mathrm{kg}$ of soil), mobile phosphorus (according to Machigin [24]) — from low to medium (16...30 mg/kg of soil), exchange potassium (according to Machigin [24]) — high (300...500 mg/kg of soil). 
In our experiments, an increase in irrigation rate under differentiated irrigation regime was due to different irrigation rates and distribution of irrigation dates by growth and development phases. For constant irrigation regime, irrigation rate was stable over all interphase periods and was within $163 \mathrm{~m}^{3} /$ ha. For differentiated irrigation regime, irrigation rate was redistributed over growth stages: during sowing and flowering $199 \mathrm{~m}^{3} /$ ha with 8 average total number of irrigations during this period, which was 3 less irrigations compared to constant irrigation regime. Under constant irrigation regime in flowering - fruit formation - milk ripeness stages, 10 irrigations $\left(163 \mathrm{~m}^{3} / \mathrm{ha}\right)$ were carried out, under differentiated irrigation - 16 irrigations $\left(127 \mathrm{~m}^{3} / \mathrm{ha}\right)$. In milk ripeness - full ripeness stage, 7 irrigations $\left(163 \mathrm{~m}^{3} / \mathrm{ha}\right)$ was performed under both irrigation regimes on average over research years.

Differentiation of irrigation regime parameters in research years was the most significant in individual phases of growth and development of tomatoes. So, in extremely arid years, the largest number of irrigations were required for all interphase periods and irrigation regimes: 28 and 30 - for constant irrigation regime in 2012 and 2014, respectively; 27 and 30 — with for differentiated regime in 2012 and 2014, respectively. The irrigation rate during this period was the largest and amounted to $5542 \mathrm{~m}^{3} /$ ha in 2012 and $5868 \mathrm{~m}^{3} /$ ha in 2014 under a constant irrigation regime, and 5906 and $6268 \mathrm{~m}^{3} /$ ha under differentiated regime in 2012 and 2014, respectively. In the most favorable hydrothermal indices in 2016, 15 irrigations were carried out with the lowest irrigation rate - $2934 \mathrm{~m}^{3} /$ ha while constantly maintaining $75 \%$ soil moisture, $3207 \mathrm{~m}^{3} / \mathrm{ha}$ for differentiated regime. However, during the growing season, differences were observed in sowing-flowering period: with a constant irrigation regime -5 , with differentiated - 1 irrigation less. Significant differences were observed in flowering fruit formation - milk ripeness period: 6 irrigations with $163 \mathrm{~m}^{3} /$ ha rate were carried out under constant irrigation regime, 10 irrigations with $127 \mathrm{~m}^{3} /$ ha rate - under differentiated irrigation. 23 irrigations $\left(4483 \mathrm{~m}^{3} / \mathrm{ha}\right)$ averaged for constant regime of irrigation in $2011-2016,22$ irrigations $\left(4804 \mathrm{~m}^{3} / \mathrm{ha}\right)$ were carried out under differentiated regime. In all cases, the irrigation rate was the main entry in water balance of tomato crops.

At the same time, in different years, depending on the prevailing weather conditions, irrigation water accounted 44.95 to $85.98 \%$ for a constant irrigation regime and 47.29 to $86.83 \%$ of total water consumption - for differentiated one. In extremely arid years, irrigation water consumption ranged from 79.19 to $80.32 \%$ (2012), from 85.98 to $86.83 \%$ (2014) of the total water consumption by vegetable plants in the experimental variants, while maintaining a constant and differentiated irrigation regimes, respectively. Water consumption in the wettest 2016 was different, when moisture supply in form of irrigation water amounted to $44.95 \%$ for constant irrigation regime and $47.29 \%$ of its total consumption for differentiated regime.

In our experiments, the total water consumption during the growing season over the research years averaged $6301.3 \mathrm{~mm}$ for constant irrigation regime, $6609.5 \mathrm{~mm}$ for differentiated regime, of which 71.0 and $72.4 \%$ were irrigations, respectively. Thus, with an increase in pre-irrigation soil moisture, the irrigation rate and the proportion of irrigation water in the total water consumption increase. 
The results showed that a smaller number of tomato fruits and a less significant average weight were found on plants grown without fertilizers in control variants for all irrigation regimes.

In terms of NPK ratios for $110,130,150 \mathrm{t} /$ ha yield of tomatoes, the number of formed fruits on one plant was higher under the differentiated irrigation regime rather than constant regime.

The combined treatment of tomato plants with mineral fertilizers + Rasvorin + Energiya-M contributed to increase in fruit number per plant under constant irrigation regime for Gerkules cultivar up to $19.4 \ldots 20.7$ fruits with $102 \ldots 107 \mathrm{~g}$ average weight, Fokker F1 hybrid generated the largest number of fruits (21.0...22.6), but the smallest average weight $(92 \ldots 98 \mathrm{~g})$, while the standard variety Volgogradsky 5/95 had $17.7 \ldots 18.7$ fruits weighing $101 \ldots 106 \mathrm{~g}$. Differentiation of irrigation rates increased number of fruits in Gerkules cultivar to $20.2 \ldots 21.8$ with $107 \ldots 112 \mathrm{~g}$ average weight. A larger number of fruits was formed on Fokker F1 hybrid - 22.7...24.1 fruits weighing $94 \ldots 101 \mathrm{~g}$, which was higher by $1.3 \ldots 1.6$ and 3.8...3.9 than the indicators on the standard variety $(103 \ldots 110 \mathrm{~g})$.

Thus, to obtain the planned productivity of $110,130,150 \mathrm{t} /$ ha in all studied tomato varieties and a hybrid (Volgogradsky 5/95, Fokker F1 and Gerkules), it is necessary to create a differentiated irrigation regime, which made it possible to obtain a $18.8 \mathrm{t} / \mathrm{ha}$ yield increase (for the planned yield of $130 \mathrm{t} / \mathrm{ha}$ ) and up to $10.2 \mathrm{t} / \mathrm{ha}$ increase (for the planned yield of $150 \mathrm{t} / \mathrm{ha}$ ) in NPK + Rasvorin + Energiya-M variant (table).

For qualitative characteristics of tomato fruits, we revealed that the most intensive accumulation of dry substances in tomato fruits was facilitated by application of the highest fertilizer doses in combination with Rastvorin and growth regulator under a differentiated irrigation regime. The increase in dry solids in this variant was $0.2 \%$ in Volgogradsky 5/95, 0.6\% in Fokker F1 hybrid and Gerkules compared to the constant irrigation regime. The experiments showed that organic acids content in tomato fruits varied slightly depending on the species, fertilizer doses and moisture conditions.

The lowest content of ascorbic acid $(0.53 \ldots 0.56 \%$ - for a constant regime of irrigation; $0.56 \%$ - for a differentiated regime of irrigation) was observed in fruits from unfertilized plots. In all variants with mineral fertilization for the planned 110, 130, $150 \mathrm{t} /$ ha yield levels, acidity of fruit was in the range of $0.61 . .0 .64 \%$ in the standard Volgogradsky $5 / 95$ variety grown under a constant irrigation regime, and $0.63 \ldots . .0 .65 \%$ under differentiation irrigation water according to growth periods.

Due to its biological characteristics, Fokker F1 hybrid and Gerkules variety accumulated a smaller amount of acids in fruits $-0.57 \ldots 0.60 \%$ under a constant irrigation regime. Under differential irrigation, Fokker F1 hybrid decreased acid level to $0.61 \ldots 0.64 \%$, and Gerkules variety increased it to $0.66 \%$ when applying fertilizers for the planned $150 \mathrm{t} /$ ha yield compared to Volgogradsky 5/95 variety. Thus, the enhanced water and nutrient soil regime had a positive effect on yields and improved biochemical fruit composition.

Economically, cultivation of Gerkules tomato under $\mathrm{N}_{285} \mathrm{P}_{115} \mathrm{~K}_{145}+$ Rastvorin + Energia-M was the most profitable. In the variants, 6.87 rubles income was achieved. 
Efficiency of the studied agricultural practices in tomato, average for 2011-2016

\begin{tabular}{|c|c|c|c|c|c|c|c|c|c|c|}
\hline \multirow{3}{*}{\multicolumn{2}{|c|}{ Variant }} & \multicolumn{3}{|c|}{ Volgogradsky 5/95 } & \multicolumn{3}{|c|}{ Fokker F1 } & \multicolumn{3}{|c|}{ Gerkules } \\
\hline & & \multicolumn{2}{|c|}{ yield, t/ha } & \multirow{2}{*}{$\begin{array}{l}\text { market- } \\
\text { ability of } \\
\text { fruits, } \%\end{array}$} & \multicolumn{2}{|c|}{ yield, t/ha } & \multirow{2}{*}{\begin{tabular}{|} 
market- \\
ability of \\
fruits, $\%$
\end{tabular}} & \multicolumn{2}{|c|}{ yield, $t / h a$} & \multirow{2}{*}{$\begin{array}{l}\text { market- } \\
\text { ability of } \\
\text { fruits, \% }\end{array}$} \\
\hline & & gross & $\begin{array}{l}\text { sal- } \\
\text { able }\end{array}$ & & gross & $\begin{array}{l}\text { sal- } \\
\text { able }\end{array}$ & & gross & \begin{tabular}{c|c} 
sal- \\
able
\end{tabular} & \\
\hline \multicolumn{11}{|c|}{$75 \ldots 75 \ldots 75 \%$ FC } \\
\hline Control & & 56.5 & 42.7 & 75.5 & 70.9 & 54.3 & 76.5 & 74.5 & 58.1 & \begin{tabular}{l|l}
1 & 77.9 \\
\end{tabular} \\
\hline Energiya-M & & 68.8 & 54.9 & 79.6 & 84.5 & 68.6 & 81.1 & 88.4 & 72.7 & \begin{tabular}{l|l}
7 & 82.2 \\
\end{tabular} \\
\hline $\mathrm{N}_{210} \mathrm{P}_{85} \mathrm{~K}_{105}$ & & 82.6 & 67.7 & 81.9 & 99.7 & 82.7 & 82.9 & 106.6 & 89.6 & \begin{tabular}{l|l}
6 & 84.0 \\
\end{tabular} \\
\hline $\mathrm{N}_{250} \mathrm{P}_{100} \mathrm{~K}_{125}$ & & 91.7 & 75.8 & 82.6 & 110.3 & 92.3 & 83.6 & 117.2 & 99.3 & \begin{tabular}{l|l}
3 & 84.7 \\
\end{tabular} \\
\hline $\mathrm{N}_{285} \mathrm{P}_{115} \mathrm{~K}_{145}$ & & 99.8 & 83.1 & 83.2 & 119.1 & 100.3 & 84.2 & 126.3 & 108.0 & \begin{tabular}{l|l}
0 & 85.5 \\
\end{tabular} \\
\hline Rastvorin & & 73.9 & 59.3 & 80.1 & 89.9 & 73.1 & 81.3 & 94.4 & 78.0 & \begin{tabular}{l|l}
0 & 82.6 \\
\end{tabular} \\
\hline $\mathrm{N}_{210} \mathrm{P}_{85} \mathrm{~K}_{105}+$ Morta & & 92.4 & 76.5 & 82.7 & 110.1 & 92.2 & 83.7 & 116.7 & 98.9 & \begin{tabular}{l|l}
9 & 84.7 \\
\end{tabular} \\
\hline $\mathrm{N}_{250} \mathrm{P}_{100} \mathrm{~K}_{125}+$ Mort & & 108.2 & 90.3 & 83.4 & 127.6 & 107.6 & 84.3 & 133.9 & 114.6 & \begin{tabular}{l|l}
6 & 85.6 \\
\end{tabular} \\
\hline $\mathrm{N}_{285} \mathrm{P}_{115} \mathrm{~K}_{145}+$ Mort & & 115.4 & 97.0 & 84.0 & 136.4 & 115.9 & 85.0 & 142.1 & 122.5 & \begin{tabular}{l|l}
5 & 86.2 \\
\end{tabular} \\
\hline Rastvorin + Energ & & 77.4 & 63.0 & 81.3 & 95.3 & 79.1 & 83.0 & 100.3 & 84.0 & \begin{tabular}{l|l}
0 & 83.8 \\
\end{tabular} \\
\hline $\mathrm{N}_{210} \mathrm{P}_{85} \mathrm{~K}_{105}+$ Rastvo & nergiya-M & 99.0 & 82.9 & 83.7 & 119.4 & 100.9 & 84.4 & 125.8 & 107.9 & 85.7 \\
\hline $\mathrm{N}_{250} \mathrm{P}_{100} \mathrm{~K}_{125}+$ Rastv & nergiya-M & 114.1 & 96.2 & 84.3 & 136.0 & 116.0 & 85.2 & 142.5 & 123.0 & 86.3 \\
\hline $\mathrm{N}_{285} \mathrm{P}_{115} \mathrm{~K}_{145}+$ Rastv & nergiya-M & 123.2 & 104.7 & 84.9 & 145.1 & 124.5 & 85.8 & 153.9 & 133.7 & 86.8 \\
\hline \multicolumn{11}{|c|}{$70 \ldots 80 \ldots 75 \%$ FC } \\
\hline Control & & 61.1 & 46.9 & 76.7 & 75.2 & 58.5 & 77.7 & 78.8 & 62.0 & 78.7 \\
\hline Energiya-M & & 72.7 & 59.0 & 81.2 & 88.8 & 73.1 & 82.3 & 92.2 & 77.0 & 83.4 \\
\hline $\mathrm{N}_{210} \mathrm{P}_{85} \mathrm{~K}_{105}$ & & 88.1 & 73.1 & 83.0 & 105.0 & 88.8 & 84.6 & 112.0 & 95.7 & 85.4 \\
\hline $\mathrm{N}_{250} \mathrm{P}_{100} \mathrm{~K}_{125}$ & & 98.3 & 82.5 & 83.8 & 116.3 & 99.3 & 85.3 & 124.0 & 107.0 & 86.3 \\
\hline $\mathrm{N}_{285} \mathrm{P}_{115} \mathrm{~K}_{145}$ & & 106.4 & 89.9 & 84.5 & 124.9 & 107.4 & 86.0 & 133.4 & 116.1 & 87.0 \\
\hline Rastvorin & & 78.3 & 64.0 & 81.6 & 94.8 & 78.5 & 82.8 & 99.1 & 82.9 & \begin{tabular}{l|l}
7 & 83.6 \\
\end{tabular} \\
\hline $\mathrm{N}_{210} \mathrm{P}_{85} \mathrm{~K}_{105}+$ Rastv & & 98.5 & 82.7 & 83.9 & 116.4 & 99.4 & 85.4 & 122.4 & 105.9 & \begin{tabular}{l|l}
7 & 86.4 \\
\end{tabular} \\
\hline $\mathrm{N}_{250} \mathrm{P}_{100} \mathrm{~K}_{125}+$ Rast & & 115.2 & 97.5 & 84.6 & 134.1 & 115.6 & 86.1 & 140.2 & 122.3 & \begin{tabular}{l|l}
3 & 87.2 \\
\end{tabular} \\
\hline $\mathrm{N}_{285} \mathrm{P}_{115} \mathrm{~K}_{145}+$ Rast & & 122.6 & 104.4 & 85.1 & 143.1 & 123.9 & 86.6 & 149.1 & 130.9 & \begin{tabular}{l|l}
3 & 87.8 \\
\end{tabular} \\
\hline Rastvorin + Energ & & 82.1 & 68.2 & 83.0 & 99.6 & 84.0 & 84.3 & 104.9 & 89.4 & \begin{tabular}{l|l}
4 & 85.2 \\
\end{tabular} \\
\hline $\mathrm{N}_{210} \mathrm{P}_{85} \mathrm{~K}_{105}+$ Rastvo & ergiya-M & 105.3 & 89.4 & 84.8 & 125.8 & 108.4 & 86.1 & 131.8 & 115.0 & 87.2 \\
\hline $\mathrm{N}_{250} \mathrm{P}_{100} \mathrm{~K}_{125}+$ Rastv & nergiya-M & 120.8 & 103.4 & 85.6 & 142.1 & 123.4 & 86.8 & 148.8 & 130.7 & 87.8 \\
\hline $\mathrm{N}_{285} \mathrm{P}_{115} \mathrm{~K}_{145}+$ Rastv & nergiya-M & 130.0 & 112.3 & 86.4 & 151.4 & 132.5 & 87.5 & 160.2 & 141.9 & \begin{tabular}{l|l}
7 & 88.5 \\
\end{tabular} \\
\hline LSD 05 (2011) & 3.94 & \multicolumn{3}{|c|}{ LSD 05 (2013) } & 4.52 & \multicolumn{3}{|c|}{ LSD 05 (2015) } & \multicolumn{2}{|c|}{4.12} \\
\hline LSD $05 \mathrm{~A}$ & 0.66 & \multicolumn{3}{|c|}{ LSD $05 \mathrm{~A}$} & 0.75 & \multicolumn{3}{|c|}{ LSD $05 \mathrm{~A}$} & \multicolumn{2}{|c|}{0.69} \\
\hline LSD 05 B & 0.80 & \multicolumn{3}{|c|}{ LSD 05 B } & 0.92 & \multicolumn{3}{|c|}{ LSD 05 B } & & 84 \\
\hline LSD $05 \mathrm{C}$ & 1.61 & LSD 0 & $5 \mathrm{C}$ & & 1.85 & & SD $05 \mathrm{C}$ & & & 68 \\
\hline LSD $05 \mathrm{AB}$ & 2.78 & LSD 0 & $5 \mathrm{AB}$ & & 3.20 & & $S D 05 A B$ & & & 91 \\
\hline LSD 05 AC & 2.27 & LSD 0 & $5 \mathrm{AC}$ & & 2.61 & & SD $05 \mathrm{AC}$ & & & 38 \\
\hline LSD 05 BC & 1.14 & LSD 0 & $5 \mathrm{BC}$ & & 1.30 & & SD 05 BC & & & .19 \\
\hline LSD 05 ABC & 0.80 & LSD 0 & $5 \mathrm{ABC}$ & & 0.92 & & SD $05 \mathrm{ABC}$ & & & .84 \\
\hline LSD 05 (2012) & 4.40 & LSD 0 & $5(2014$ & & 4.30 & & SD 05 (20 & 16) & & .41 \\
\hline LSD $05 \mathrm{~A}$ & 0.73 & LSD 0 & $5 \mathrm{~A}$ & & 0.72 & & SD $05 \mathrm{~A}$ & & & .73 \\
\hline LSD 05 B & 0.90 & LSD 0 & $5 B$ & & 0.88 & & SD 05 B & & & .90 \\
\hline LSD 05 C & 1.80 & LSD 0 & $5 \mathrm{C}$ & & 1.75 & & SD $05 \mathrm{C}$ & & & .80 \\
\hline LSD $05 \mathrm{AB}$ & 3.11 & LSD 0 & $5 \mathrm{AB}$ & & 3.04 & & SD $05 \mathrm{AB}$ & & & 12 \\
\hline LSD 05 AC & 2.54 & LSD 0 & $5 \mathrm{AC}$ & & 2.48 & & SD $05 \mathrm{AC}$ & & & .54 \\
\hline LSD 05 BC & 1.27 & LSD 0 & $5 \mathrm{BC}$ & & 1.24 & & SD 05 BC & & & .27 \\
\hline LSD 05 ABC & 0.90 & LSD 0 & $5 \mathrm{ABC}$ & & 0.88 & & SD $05 \mathrm{ABC}$ & & & .90 \\
\hline
\end{tabular}




\section{Conclusions}

In order to obtain high-quality and guaranteed tomato harvests under conditions of unstable moistening of the Lower Volga region in the subzone of light chestnut soils, we recommend applying a differential irrigation regime depending on tomato growth stages (for middle-late varieties): from seedlings to flowering — not less than $70 \% \mathrm{FC}$, from beginning of flowering to beginning of fruit formation - $80 \% \mathrm{FC}$, from beginning of fruit formation to the last harvesting — not less than 75\% FC. Agro-ecological assessment of varieties and hybrids of the studied tomato plants of Russian and foreign breeding allows us to recommend a medium-late tomato variety Gerkules bred at the Crimean experimental-breeding station of Vavilov Institute of Plant Genetic Resources for cultivation under drip irrigation. Under differentiated irrigation regime, the optimal fertilizing was the integrated use of the estimated doses of mineral, water-soluble fertilizers and growth regulators (doses recommended in the pesticides and agrochemicals reference book) throughout the growing season, so, $\mathrm{N}_{285} \mathrm{P}_{115} \mathrm{~K}_{145}+$ Rastvorin + Energiya-M was effective for tomato with the planned $150 \mathrm{t} /$ ha yield.

\section{Введение}

Овощеводство - одна из основных отраслей АПК, обеспечивающая круглогодично население витаминами $\mathrm{C}, \mathrm{B}, \mathrm{B}_{2}, \mathrm{~A}, \mathrm{H}, \mathrm{B}_{9}$, пектиновыми, ценными минеральными, а также питательными и другими веществами, которые определяют здоровое питание человека [1-3].

В Российской Федерации основные площади, занятые овощными культурами, в т.ч. томатами, находятся в южных регионах. Нижнее Поволжье принято считать «всероссийским огородом». Регион располагает благоприятными природно-климатическими условиями для развития овощеводства и в результате занимает лидирующее место в стране по производству овощей. Орошение здесь определяет судьбу этой отрасли, так как орошаемое земледелие, занимая 53\% площади пашни, дает 90\% всей валовой продукции [4]. Производство овощей в данном регионе находится на стабильно высоких отметках - сборы овощей открытого грунта в промышленном секторе овощеводства составили в 2016 г. 531,3 тыс. т - 11,6\% от общих сборов по РФ, это второе место среди регионов России. Второе место принадлежит овощным культурам и по посевным площадям - 15,6 тыс. га, что составляет $8,3 \%$ от всех площадей [5].

Томаты являются одним из наиболее ценных в питательном отношении овощем. Плоды томатов содержат сахара, кислоты, ароматические вещества, а также большое количество витаминов. Высокие вкусовые, питательные и диетические качества, а также разнообразные способы приготовления сделали томаты популярным овощем $[3,6]$.

В настоящее время производство овощей открытого грунта ведется в основном без применения капельного орошения, учета степени адаптивности сортов и гибридов к климатическим условиям [7-9]. 
Высокие урожаи в сочетании с высоким качеством плодов являются общим требованием производителей томата, и это может быть достигнуто только при учете критических производственных факторов. К ним относятся надлежащее управление ирригацией, выбор сортов, профилактика заболеваний, плодородие почв, климат и т.д. Многие авторы установили, что соблюдение агротехнологических приемов при ключевой роли питания определяет качество и урожайность томатов [10-17].

В связи с этим изучение ресурсосберегающих приемов увеличения урожайности овощных культур, в т.ч. микроорошения, водорастворимых удобрений и стимуляторов роста, видится нам актуальным.

Цель исследований - рационализировать технологические приемы для получения урожайности 150 и более т/га высококачественной овощной продукции в соответствии со складывающимися природно-климатическими условиями Нижнего Поволжья.

\section{Материалы и методы}

Исследования в опыте осуществлялись согласно «Методика опытного дела в овощеводстве и бахчеводстве» [18], «Методика полевого опыта» [19-20], «Агрофизические и агрохимические методы исследования почв» [21].

Опыт закладывался методом расщепленных делянок. Расположение делянок по сортам и гибридам - систематическое, по питательным режимам - рендомизированное. Учетная площадь делянок первого порядка (по водному режиму)

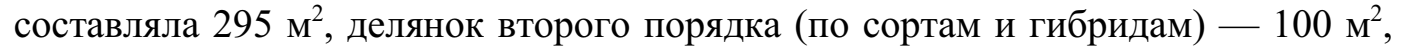
делянок третьего порядка (по питательным режимам) - 7,5 м². Повторность опыта - трехкратная. Схема посева семян томата $0,50+0,90$ м.

Фактор $A$ - агроэкологическая оценка сортов и гибридов отечественной и зарубежной селекции. Объектами исследования культуры томата изучались следующие сорта и гибриды: Волгоградский 5/95 (сорт-стандарт), гибрид Фоккер $\mathrm{F}_{1}$, сорт Геркулес.

Фактор $B$ - научное обоснование управлением продуктивностью планируемых уровней урожайности томата: $110,130,150$ т/га. Варианты опытов:

1) контроль;

2) обработка регулятором роста Энергия-М;

3) внесение минеральных удобрений под урожайность 110 т/га: $\mathrm{N}$ 210 кг/га д.в.; $\mathrm{P}_{2} \mathrm{O}_{5}-85, \mathrm{~K}_{2} \mathrm{O}-105$ кг/га д.в.;

4) внесение минеральных удобрений под урожайность 130 т/га: $\mathrm{N}-250$ кг/га д.в.; $\mathrm{P}_{2} \mathrm{O}_{5}-100, \mathrm{~K}_{2} \mathrm{O}-125$ кг/га д.в.;

5) внесение минеральных удобрений под урожайность 150 т/га: $\mathrm{N}$ 285 кг/га д.в.; $\mathrm{P}_{2} \mathrm{O}_{5}-115, \mathrm{~K}_{2} \mathrm{O}-145$ кг/га д.в.;

6) внесение водорастворимого удобрения Растворин;

7) комплексная обработка водорастворимым удобрением и регулятором роста Энергия-М;

8) комплексная обработка минеральными, водорастворимым удобрениями и регулятором роста Энергия-М под урожайность 110 т/га; 
9) комплексная обработка минеральными, водорастворимым удобрениями и регулятором роста Энергия-М под урожайность 130 т/га;

10) комплексная обработка минеральными, водорастворимым удобрениями и регулятором роста Энергия-М под урожайность 150 т/га.

Фактор $C$ - влияние режимов орошения на продуктивность томата:

1) поддержание предполивного порога влажности на уровне $75 \ldots 75 \ldots 75 \%$ НВ (постоянный режим орошения);

2) поддержание предполивного порога влажности на уровне $70 \ldots 80 \ldots 75 \% \mathrm{HB}$ (дифференцированный режим орошения): посев - цветение - 70\% НВ; цветение - молочная спелость - 80\% НВ; молочная спелость - полная спелость $75 \% \mathrm{HB}$.

В качестве минеральных удобрений исследовали аммиачную селитру, двойной суперфосфат и хлористый калий. Для полива на опытном участке была смонтирована система капельного орошения конструкции «Неодрип» в комплекте с капельными трубопроводами с водовыпусками через каждые 0,3 м и производительностью капельниц 1,55 л/ч. Поливные трубопроводы системы капельного орошения укладывали одновременно во время посева культур.

Первая подкормка выполнялась при появлении 5..7 листовых пластин, разводили $10 \ldots 15$ г удобрения Растворин на 10 л воды. В период плодоношения применяли раствор концентрацией 25 г на 10 л воды. Опрыскивание проводили этим раствором через 7..10 сут. Наличие нескольких марок позволяло комбинировать подкормки в зависимости от фазы развития растений. Схема обработки регулятором роста Энергия-М включала: 1) замачивание семян (1 мл / 1 кг семян) в течение $30 \ldots 40$ мин с расходом рабочего раствора 2 л/кг; 2) последующие опрыскивания (15 г/га) и некорневые подкормки (на площади 1 га в дозе 15 г на 300 г воды) в начальный период роста, в фазу бутонизация - начала цветения.

\section{Результаты и обсуждение исследований}

Исследования были проведены в 2011-2016 гг. в хозяйстве ИП Зайцева В.А., Городищенском районе Волгоградской области. Гранулометрический состав исследуемых почв на $80 \%$ территории тяжелосуглинистый и отличался невысоким $(2,31 \%)$ содержанием гумуса в пахотном горизонте, а на глубине $0,4 \ldots 1,0$ м его количество снижалось с 1,05 до 0,32\%. Бедность этой почвы гумусом объясняется тем, что процессы превращения органических веществ в зоне каштановых почв имеют специфический зональный характер. В прямой зависимости от гранулометрического состава находятся водно-физические свойства почв. Плотность сложения варьировала по горизонтам, наименьшая была отмечена в слое $0,0 \ldots 0,1$ м $1,24 \mathrm{~T} / \mathrm{M}^{3}$. С дальнейшим углублением этот показатель увеличивался в исследуемом слое почвы $0,0 \ldots 0,6 \mathrm{M}$ - до $1,35 \mathrm{~T} / \mathrm{m}^{3}$, в слое $0,0 \ldots 1,0 \mathrm{M}$ - до 1,45 т/м $\mathrm{M}^{3}$. Наибольшая плотность сложения была отмечена на глубине 1 м и составляла 1,62 т/м³. Общая порозность пахотного слоя почвы варьировала от 50,4 до 47,5\%. Наименьшая влагоемкость колебалась от $25,60 \%$ в слое $0,0 \ldots 0,1$ м до $22,82 \%$ в слое 0,0...0,6 м. Наименьшая влагоемкость составляла 20,4\%, влажность завядания $8,49 \%$ в среднем для слоя $0,0 \ldots 1,0$ м; $\mathrm{pH}$ почвенного раствора — $6,8 \ldots 8,0$. Обеспе- 
ченность почвы опытного участка гидролизуемым азотом (по Корнфильду [2223]) — низкая (менее 100 мг/кг почвы), подвижным фосфором (по Мачигину [24]) от низкой до средней (16...30 мг/кг почвы), обменным калием (по Мачигину [24]) повышенная и высокая (300...500 мг/кг).

В наших опытах в посевах томата повышение оросительной нормы при дифференцированном режиме орошения складывалось за счет различной поливной нормы и распределения сроков проведения поливов по фазам роста и развития. При постоянном режиме орошения поливная норма была стабильной по всем межфазным периодам и находилась в пределах 163 м³/га. При дифференцированном режиме орошения происходило перераспределение поливной нормы по фазам вегетации: в фазу посев - цветение - 199 м³/га общим количеством поливов в этот период в среднем по годам - 8, что меньше на 3 полива по сравнению с постоянным режимом орошения. В фазу цветение - плодообразование - молочная спелость при постоянном режиме орошения было проведено 10 поливов нормой $163 \mathrm{~m}^{3} /$ га, при дифференцированном - на 6 поливов больше поливной нормой 127 м³/га. В межфазный период молочная спелость - полная спелость при обоих режимах орошения полив проводился поливной нормой 163 м²/га с одинаковым количеством поливов - 7 в среднем по годам закладки опыта.

Наиболее была заметна по годам исследований дифференциация параметров поливного режима в отдельные фазы роста и развития томатов. Так в острозасушливые годы требовалось наибольшее количество поливов по всем межфазным периодам и режимам орошения: при постоянном режиме орошения в 2012 г. - 28, в 2014 г. - 30, при дифференцированном режиме - 27 и 30 соответственно по годам. Оросительная норма в этот период исследований была наибольшей и составила при постоянном режиме орошения в 2012 г. - 5542 м $3 /$ га, в 2014 г. $5868 \mathrm{~m}^{3} /$ га, при дифференцированном режиме - 5906 и $6268 \mathrm{~m}^{3} /$ га соответственно по годам. В наиболее благоприятном по гидротермическим показателям 2016 г. было проведено 15 поливов наименьшей оросительной нормой при постоянном поддержании влажности почвы 75\% - 2934 м 3 га, при дифференцированном $3207 \mathrm{~m}^{3} /$ га. Однако, в течение вегетации наблюдались различия в межфазный период посев - цветение: при постоянном режиме орошения - 5, при дифференцированном - на 1 полив меньше. Существенные различия наблюдались в фазу цветение - плодообразование - молочная спелость: при постоянном режиме

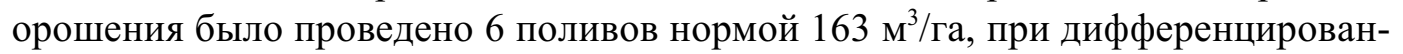
ном - на 4 полива больше поливной нормой $127 \mathrm{~m}^{3} /$ га. В среднем за $2011-$ 2016 гг. при постоянном режиме орошения было проведено 23 полива оросительной нормой $4483 \mathrm{~m}^{3} /$ га, при дифференцированном - 22 полива оросительной нормой $4804 \mathrm{~m}^{3} /$ га. Во всех вариантах основной приходной статьей водного баланса посевов томатов являлась оросительная норма.

При этом в разные годы, в зависимости от складывающихся погодных условий, на долю воды за счет поливов приходилось при постоянном режиме орошения от 44,95 до $85,98 \%$, при дифференцированном - от 47,29 до $86,83 \%$ от общего водопотребления. В острозасушливых расход поливной воды по вариантам опыта варьировал в пределах от 79,19 до 80,32\% (2012 г.), от 85,98 до 86,83\% (2014 г.) 
общего расхода воды овощными растениями, соответственно при поддержании постоянного и дифференцированного режимов орошения. Несколько отличной была структура водопотребления в самом влажном 2016 г., когда приход влаги в виде оросительной воды при постоянном режиме орошения составил 44,95\%, при дифференцированном — 47,29\% от общего ее расхода.

В наших опытах суммарное водопотребление в течение всего периода вегетации в среднем за годы исследований составило при постоянном режиме орошения - 6301,3 мм, при дифференцированном - 6609,5 мм, из них за счет поливов 71,0 и 72,4\% соответственно по режимам орошения. Таким образом, с повышением предполивной влажности почвы увеличивается оросительная норма и доля участия оросительной воды в суммарном водопотреблении.

Проведенные учеты показали, что меньшее количество плодов томата и менее значительный их средний вес были установлены на растениях, выращенных без удобрений на контрольных вариантах по всем режимам орошения.

Что касается вариантов с различным соотношением NPK на планируемую урожайность томатов 110, 130, 150 т/га, то количество сформировавшихся плодов на одном кусте было при дифференцированном режиме орошения по всем вариантам опыта выше, чем при постоянном режиме.

Комплексная обработка растений томатов минеральными удобрениями + Растворин + Энергия-М способствовала увеличению количества плодов на кусте при постоянном режиме орошения по сорту Геркулес до 19,4...20,7 шт. при среднем их весе 102...107 г., на гибриде Фоккер $\mathrm{F}_{1}$ сформировалось наибольшее количество плодов - 21,0..22,6 шт., но наименьшей средней массой — $92 \ldots 98$ г, в то время, как на сорте-стандарте Волгоградский 5/95 - 17,7..18,7 шт. массой $101 \ldots 106$ г. Дифференциация поливных норм повышала количество плодов по сорту Геркулес до 20,2 ..21,8 шт. при среднем их весе $107 \ldots 112$ г, на гибриде Фоккер $\mathrm{F}_{1}$ сформировалось большее количество плодов - 22,7..24,1 шт. массой 94...101 г, что выше показателей на сорте-стандарте на 1,3..1,6 и 3,8 ...3,9 шт., при этом их масса составляла $103 \ldots 110$ г.

На культуре томат на всех исследуемых сортах и гибриде (Волгоградский 5/95, Фоккер $\mathrm{F}_{1}$ и Геркулес) для получения планируемой продуктивности в 110,130 , 150 т/га необходимо создавать дифференцированный режим орошения, что давало возможность получать прибавку урожайности до 18,8 т/га (на планируемую урожайность 130 т/га) и до 10,2 т/га (на планируемую урожайность 150 т/га) в вариантах NPK + Растворин + Энергия-М (табл.).

При установлении качественных характеристик плодов томата нами было выявлено, что наиболее интенсивному накоплению сухих веществ в плодах томата способствовало внесение самых высоких доз удобрений в комплексе с Растворином и регулятором роста при дифференцированном режиме орошения. Прибавка сухих веществ на этом варианте по сравнению с постоянным режимом орошения составила на сорте-стандарте Волгоградский 5/95 0,2\%, на гибриде Фоккер F1 и на сорте Геркулес - 0,6\%. Проведенные опыты показали, что содержание органических кислот в плодах томатов незначительно варьировало в зависимости от видов, доз удобрений и условий увлажнения. 

ость исследуемых агроприемов в посевах томата, среднее за 2011-2016 гг.

\begin{tabular}{|c|c|c|c|c|c|c|c|c|c|c|}
\hline \multirow{3}{*}{\multicolumn{2}{|c|}{ Вариант опыта }} & \multicolumn{3}{|c|}{ Волгоградский 5/95 } & \multicolumn{3}{|c|}{ Фоккер F1 } & \multicolumn{3}{|c|}{ Геркулес } \\
\hline & & \multicolumn{2}{|c|}{$\begin{array}{l}\text { Урожай- } \\
\text { ность, т/га }\end{array}$} & \multirow{2}{*}{$\begin{array}{c}\text { Товар- } \\
\text { ность } \\
\text { плодов, } \\
\%\end{array}$} & \multicolumn{2}{|c|}{$\begin{array}{c}\text { Урожай- } \\
\text { ность, т/га }\end{array}$} & \multirow{2}{*}{\begin{tabular}{|c|} 
Товар- \\
ность \\
плодов, \\
$\%$
\end{tabular}} & \multicolumn{2}{|c|}{$\begin{array}{l}\text { Урожай- } \\
\text { ность, т/га }\end{array}$} & \multirow{2}{*}{$\begin{array}{c}\text { Товар- } \\
\text { ность } \\
\text { плодов, } \\
\%\end{array}$} \\
\hline & & $\begin{array}{l}\text { об- } \\
\text { щая }\end{array}$ & $\begin{array}{l}\text { товар- } \\
\text { ная }\end{array}$ & & $\begin{array}{l}\text { об- } \\
\text { щая }\end{array}$ & $\begin{array}{c}\text { товар- } \\
\text { ная }\end{array}$ & & \begin{tabular}{c|} 
об- \\
щая
\end{tabular} & $\begin{array}{c}\text { то- } \\
\text { вар- } \\
\text { ная }\end{array}$ & \\
\hline \multicolumn{11}{|c|}{$75 \ldots 75 \ldots 75 \% \mathrm{HB}$} \\
\hline Контроль & & 56.5 & 42.7 & 75.5 & 70.9 & 54.3 & 76.5 & 74.5 & 58.1 & 77.9 \\
\hline Энергия-М & & 68.8 & 54.9 & 79.6 & 84.5 & 68.6 & 81.1 & 88.4 & 72.7 & 82.2 \\
\hline $\mathrm{N}_{210} \mathrm{P}_{85} \mathrm{~K}_{105}$ & & 82.6 & 67.7 & 81.9 & 99.7 & 82.7 & 82.9 & 106.6 & 89.6 & \begin{tabular}{l|l}
6 & 84.0 \\
\end{tabular} \\
\hline $\mathrm{N}_{250} \mathrm{P}_{100} \mathrm{~K}_{125}$ & & 91.7 & 75.8 & 82.6 & 110.3 & 92.3 & 83.6 & 117.2 & 99.3 & \begin{tabular}{l|l}
3 & 84.7 \\
\end{tabular} \\
\hline $\mathrm{N}_{285} \mathrm{P}_{115} \mathrm{~K}_{145}$ & & 99.8 & 83.1 & 83.2 & 119.1 & 100.3 & 84.2 & 126.3 & \begin{tabular}{|l|l|}
3 & 108.0 \\
\end{tabular} & 85.5 \\
\hline Растворин & & 73.9 & 59.3 & 80.1 & 89.9 & 73.1 & 81.3 & 94.4 & 78.0 & \begin{tabular}{l|l}
0 & 82.6 \\
\end{tabular} \\
\hline $\mathrm{N}_{210} \mathrm{P}_{85} \mathrm{~K}_{105}+$ PactB & & 92.4 & 76.5 & 82.7 & \begin{tabular}{|l|}
110.1 \\
\end{tabular} & 92.2 & 83.7 & 116.7 & 98.5 & \begin{tabular}{l|l}
9 & 84.7 \\
\end{tabular} \\
\hline $\mathrm{N}_{250} \mathrm{P}_{100} \mathrm{~K}_{125}+\mathrm{PaCT}$ & & 108.2 & 90.3 & 83.4 & \begin{tabular}{|l|l|}
127.6 \\
\end{tabular} & \begin{tabular}{|l|}
107.6 \\
\end{tabular} & 84.3 & 133.9 & \begin{tabular}{|l|l|}
9 & 114.6 \\
\end{tabular} & \begin{tabular}{l|l}
6 & 85.6 \\
\end{tabular} \\
\hline $\mathrm{N}_{285} \mathrm{P}_{115} \mathrm{~K}_{145}+\mathrm{Pact}$ & & 115.4 & 97.0 & 84.0 & 136.4 & 115.9 & 85.0 & 142.1 & 1122.5 & 86.2 \\
\hline Растворин + Энер & & 77.4 & 63.0 & 81.3 & 95.3 & 79.1 & 83.0 & 100.3 & 84.0 & 83.8 \\
\hline $\mathrm{N}_{210} \mathrm{P}_{85} \mathrm{~K}_{105}+$ Раство & нергия-М & 99.0 & 82.9 & 83.7 & 119.4 & 100.9 & 84.4 & 125.8 & \begin{tabular}{l|l}
3 & 107.9 \\
\end{tabular} & \begin{tabular}{l|l}
9 & 85.7 \\
\end{tabular} \\
\hline $\mathrm{N}_{250} \mathrm{P}_{100} \mathrm{~K}_{125}+$ PaствC & энергия-М & 114.1 & 96.2 & 84.3 & 136.0 & 116.0 & 85.2 & 142.5 & 5123.0 & \begin{tabular}{l|l}
0 & 86.3 \\
\end{tabular} \\
\hline $\mathrm{N}_{285} \mathrm{P}_{115} \mathrm{~K}_{145}+$ PactBC & нергия-М & 123.2 & 104.7 & 84.9 & \begin{tabular}{|l|}
145.1 \\
\end{tabular} & 124.5 & 85.8 & 153.9 & \begin{tabular}{|l|l|}
9 & 133.7 \\
\end{tabular} & \begin{tabular}{l|l}
7 & 86.8 \\
\end{tabular} \\
\hline \multicolumn{11}{|c|}{$70 \ldots 80 \ldots 75 \%$ HB } \\
\hline Контроль & & 61.1 & 46.9 & 76.7 & 75.2 & 58.5 & 77.7 & 78.8 & 62.0 & 78.7 \\
\hline Энергия-М & & 72.7 & 59.0 & 81.2 & 88.8 & 73.1 & 82.3 & 92.2 & 77.0 & 83.4 \\
\hline $\mathrm{N}_{210} \mathrm{P}_{85} \mathrm{~K}_{105}$ & & 88.1 & 73.1 & 83.0 & 105.0 & 88.8 & 84.6 & 112.0 & 95.7 & 85.4 \\
\hline $\mathrm{N}_{250} \mathrm{P}_{100} \mathrm{~K}_{125}$ & & 98.3 & 82.5 & 83.8 & 116.3 & 99.3 & 85.3 & 124.0 & 107.0 & 86.3 \\
\hline $\mathrm{N}_{285} \mathrm{P}_{115} \mathrm{~K}_{145}$ & & 106.4 & 89.9 & 84.5 & 124.9 & 107.4 & 86.0 & 133.4 & 116.1 & 87.0 \\
\hline Rastvorin & & 78.3 & 64.0 & 81.6 & 94.8 & 78.5 & 82.8 & 99.1 & 82.9 & 83.6 \\
\hline $\mathrm{N}_{210} \mathrm{P}_{85} \mathrm{~K}_{105}+$ Pacte & & 98.5 & 82.7 & 83.9 & 116.4 & 99.4 & 85.4 & 122.4 & 105.9 & \begin{tabular}{l|l}
9 & 86.4 \\
\end{tabular} \\
\hline $\mathrm{N}_{250} \mathrm{P}_{100} \mathrm{~K}_{125}+$ Pact & & 115.2 & 97.5 & 84.6 & 134.1 & 115.6 & 86.1 & 140.2 & 122.3 & 87.2 \\
\hline $\mathrm{N}_{285} \mathrm{P}_{115} \mathrm{~K}_{145}+\mathrm{Pact}$ & & 122.6 & 104.4 & 85.1 & 143.1 & 123.9 & 86.6 & \begin{tabular}{|l|}
149.1 \\
\end{tabular} & 130.9 & 87.8 \\
\hline Rastvorin + Энер & & 82.1 & 68.2 & 83.0 & 99.6 & 84.0 & 84.3 & 104.9 & 89.4 & \begin{tabular}{l|l}
4 & 85.2 \\
\end{tabular} \\
\hline $\mathrm{N}_{210} \mathrm{P}_{85} \mathrm{~K}_{105}+$ Раство & нергия-М & 105.3 & 89.4 & 84.8 & 125.8 & 108.4 & 86.1 & 131.8 & 115.0 & 87.2 \\
\hline $\mathrm{N}_{250} \mathrm{P}_{100} \mathrm{~K}_{125}+$ PactBC & энергия-М & 120.8 & 103.4 & 85.6 & 142.1 & 123.4 & 86.8 & 148.8 & 130.7 & 87.8 \\
\hline $\mathrm{N}_{285} \mathrm{P}_{115} \mathrm{~K}_{145}+$ РаствС & нергия-М & 130.0 & 112.3 & 86.4 & 151.4 & 132.5 & 87.5 & 160.2 & 141.9 & \begin{tabular}{l|l}
9 & 88.5 \\
\end{tabular} \\
\hline HCP 05 (2011) & 3.94 & \multicolumn{3}{|c|}{ HCP 05 (2013) } & 4.52 & \multicolumn{3}{|c|}{ HCP 05 (2015) } & \multicolumn{2}{|c|}{4.12} \\
\hline HCP $05 \mathrm{~A}$ & 0.66 & \multicolumn{3}{|c|}{ HCP 05 A } & 0.75 & \multicolumn{3}{|c|}{ HCP 05 A } & \multicolumn{2}{|c|}{0.69} \\
\hline HCP 05 B & 0.80 & \multicolumn{3}{|c|}{ HCP 05 B } & 0.92 & \multicolumn{3}{|c|}{ HCP 05 B } & & .84 \\
\hline HCP 05 C & 1.61 & $\mathrm{HCP} O$ & $5 \mathrm{C}$ & & 1.85 & & CP $05 \mathrm{C}$ & & & 1.68 \\
\hline HCP 05 AB & 2.78 & $\mathrm{HCP} O$ & $5 \mathrm{AB}$ & & 3.20 & & $\mathrm{CP} 05 \mathrm{AB}$ & & & 2.91 \\
\hline HCP 05 AC & 2.27 & $\mathrm{HCP} 0$ & $5 \mathrm{AC}$ & & 2.61 & & CP 05 AC & & & 2.38 \\
\hline HCP 05 BC & 1.14 & $\mathrm{HCP} O$ & $5 \mathrm{BC}$ & & 1.30 & & CP 05 BC & & & 1.19 \\
\hline HCP 05 ABC & 0.80 & $\mathrm{HCP} 0$ & $5 \mathrm{ABC}$ & & 0.92 & & $\mathrm{CP} 05 \mathrm{ABC}$ & & & .84 \\
\hline HCP 05 (2012) & 4.40 & HCP C & $5(201$ & & 4.30 & & CP $05(2 C$ & 16) & & 1.41 \\
\hline HCP $05 \mathrm{~A}$ & 0.73 & $\mathrm{HCP} O$ & $5 \mathrm{~A}$ & & 0.72 & & CP $05 \mathrm{~A}$ & & & .73 \\
\hline HCP 05 B & 0.90 & $\mathrm{HCP} O$ & $5 \mathrm{~B}$ & & 0.88 & & CP 05 B & & & .90 \\
\hline HCP 05 C & 1.80 & HCP 0 & $5 \mathrm{C}$ & & 1.75 & & CP $05 \mathrm{C}$ & & & 1.80 \\
\hline HCP 05 AB & 3.11 & $\mathrm{HCP} O$ & $5 \mathrm{AB}$ & & 3.04 & & $\mathrm{CP} 05 \mathrm{AB}$ & & & 3.12 \\
\hline HCP 05 AC & 2.54 & HCP 0 & $5 \mathrm{AC}$ & & 2.48 & & CP 05 AC & & & 2.54 \\
\hline HCP 05 BC & 1.27 & HCP 0 & $5 \mathrm{BC}$ & & 1.24 & & CP 05 BC & & & 1.27 \\
\hline HCP 05 ABC & 0.90 & $\mathrm{HCP} 0$ & $5 \mathrm{ABC}$ & & 0.88 & & $\mathrm{CP} 05 \mathrm{ABC}$ & & & .90 \\
\hline
\end{tabular}


Наиболее низкое содержание аскорбиновой кислоты $(0,53 \ldots 0,56 \%$ - при постоянном режиме орошения; $0,56 \%$ - при дифференцированном режиме орошения) было отмечено у плодов с неудобренных делянок, соответственно по сортам и гибридам. На всех вариантах, где вносилось минеральное удобрение под планируемые уровни урожайности 110, 130, 150 т/га, кислотность плодов была в пределах 0,61...0,64\% на сорте-стандарте Волгоградский 5/95 при постоянном режиме орошения, $0,63 \ldots 0,65 \%$ - при дифференциации поливной воды по периодам роста.

$\mathrm{B}$ силу своих биологических особенностей гибрид Фоккер $\mathrm{F}_{1}$ и сорт Геркулес накапливали меньшее количество кислоты в плодах - 0,57...0,60\% при постоянном режиме орошения. При дифференцированном режиме на гибриде Фоккер $\mathrm{F}_{1}$ происходило снижение уровня кислоты до $0,61 \ldots 0,64 \%$, относительно варианта Волгоградский 5/95, а на сорте Геркулес - увеличение до 0,66\% при внесении удобрений на планируемую урожайность 150 т/га. Таким образом, усиленный водный и питательный режим почвы оказывал положительное влияние на повышение урожайности с улучшением биохимического состава плодов.

Для производителя наиболее экономически оправданным являлось возделывание томата сорта Геркулес на фоне $\mathrm{N}_{285} \mathrm{P}_{115} \mathrm{~K}_{145}+$ Растворин+Энергия-М. По вариантам достигалась окупаемость производственных затрат в сумме 6,87 рублей дохода.

\section{Выводы}

С целью получения высококачественных и гарантированных урожаев томата в условиях неустойчивого увлажнения Нижнего Поволжья в подзоне светло-каштановых почв рекомендуем применять различный режим орошения по фазам вегетации томата (для среднепоздних) - от всходов до цветения - не ниже $70 \% \mathrm{HB}$, от начала цветения до начала плодообразования - 80\% НB, от начала плодоношения до последней уборки - не ниже 75\% НВ. Агроэкологическая оценка сортов и гибридов исследуемой культуры отечественной и зарубежной селекции для выращивания в условиях капельного орошения позволяет рекомендовать среднепоздний сорт томата Геркулес, выведенный на Крымской опытно-селекционной станции Всероссийского НИИ растениеводства. При дифференцированном режиме орошения оптимальным питательным режимом является комплексное применение в течение всей вегетации расчетных доз на планируемую урожайность минеральных, водорастворимых удобрений и росторегуляторов (дозы, рекомендуемые по справочнику пестицидов и агрохимикатов) по культуре томат на планируемую урожайность 150 т/га $-\mathrm{N}_{285} \mathrm{P}_{115} \mathrm{~K}_{145}+$ Растворин + Энергия-М.

\section{References}

1. Soldatenko AV, Razin AF, Pivovarov VF, Shatilov MV, Ivanova MI, Rossinskaya OV, Razin OA. Vegetables in the system of ensuring food security of Russia. Vegetable crops of Russia. 2019; (2): 9-15. (In Russ). doi: 10.18619/2072-9146-2019-2-9-15

2. Enujeke EC, Emuh FN. Evaluation of some growth and yield indices of five varieties of tomato (Lycopersicon esculentum Mill) in Asaba Area of Delta State, Nigeria. Global Journal of BioScience and Biotechnology. 2015; 4(1):21-26. 
3. Bolkunov AI. Chemical composition and nutritional value of onions. In: Prioritetnye napravleniya razvitiya sovremennoi nauki molodykh uchenykh agrariev: Conference proceeding. Solenoe Zaimishche: Caspian Research Institute of Arid Agriculture Publ.; 2016. p. 257-301. (In Russ).

4. Gish RA, Gikalo GS. Ovoshchevodstvo yuga Rossii [Vegetable growing in the south of Russia]. Krasnodar: EDVI Publ.; 2012. (In Russ).

5. Federal service of state statistics. Itogi Vserossiiskoi sel'skokhozyaistvennoi perepisi 2016 goda. Zemel'nye resursy $i$ ikh ispol'zovanie [Results of the 2016 Russian Agricultural Census. Land resources and their use]. 3rd ed. Moscow: Statistika Rossii Publ.; 2018. (In Russ).

6. Kalmykova EV, Pleskachev YN, Kalmykova OV, Zvolinsky VP. Influence of macro- and microfertilizers for quality of tomato fruits. Proceedings of Nizhnevolzskiy agrouniversity complex: science and higher vocational education. 2019; (1):32 - 41. (In Russ). doi: 10.32786/20719485-2019-01-3

7. Tyutyuma NV, Solodovnikov AP, Mukhortova TV, Kudryashova NI. Determination of the optimum mode of irrigation and the level of mineral nutrition of hybrids of tomatoes of Russian breeding in the conditions of the north of the Astrakhan region. The Agrarian scientific journal. 2017; (8):32-38. (In Russ).

8. Petrov NY, Kalmykova EV, Ubushaeva SV, Batyrov VA. Influence of agrotechnic means on growth, development and productivity of tomato under the conditions of the Lower Volga region. Proceedings of Nizhnevolzskiy agrouniversity complex: science and higher vocational education. 2017;(2):118-125. (In Russ).

9. Soldatenko AV, Pivovarov VF, Razin AF, Shatilov MV, Razin OA, Rossinskaya OV, Bashkirov OV. Problems of production of competitive vegetable products. Vegetable crops of Russia. 2019; (1):3-7. (In Russ). doi: 10.18619/2072-9146-2019-1-3-7

10. Kurbanov SA, Magomedova DS, Dzhambulatova AZ. Tomatoes irrigation methods on meadow chestnut soils in the Republic of Dagestan. Scientific Life. 2019; (2):6-13. (In Russ).

11. Chauhan SA, Patel NB, Mehta DR, Patel JB, Zalaishita M, Vaja AD. Effect of plant growth regulators on seed yield and its parameters of tomato (Lycopersicon esculentum L). International Journal of Agriculture Sciences. 2017; 9(8):3906-3909.

12. Akand MH, Mazed HEMK, Islam MA, Pulok MAI, Chowdhury MHN, Moonmoon JF. Growth and yield of tomato (Lycopersicon esculentum Mill.) as influenced by different level of gibberellic acid application. Int J of Appl Res. 2015; 1(3):71-74.

13. Bairambekov SB, Korneva OG, Polyakova EV, Gulyaeva GV, Sokolov AS. Agricultural and chemical methods of weeds control in the vegetable crop rotation link. Ecology, Environment and Conservation. 2017; 23(3):1684-1690.

14. Sokolov AS, Bayrambekov SB, Sokolova GF. Influence of soil dressing, fertilizers, herbicides upon pollution and yeilds of vegetable cultures in sawing turnover. Advances in current natural sciences. 2018; (8):78-84. (In Russ).

15. Komarov VN, Kiseleva NN, Vorontsova AI. The use of technological methods of tomato cultivation under drip irrigation. In: Melioratsiya i problemy vosstanovleniya sel"skogo khozyaistva v Rossii: Conference proceeding. Moscow: Pryanishnikov Russian Research Institute of Agrochemistry Publ.; 2013. p. 163-166. (In Russ).

16. Gaplaev MS. Development of vegetable growing in Chechen Republic: state and prospects. Potato and vegetables. 2015; (8):2. (In Russ).

17. Gerszberg A, Katarzyna HK, Kowalczyk T, Kononowicz AK. Tomato (Solanum lycopersicum L.) in the service of biotechnology. Plant Cell Tiss Organ Cult. 2015; 120(3):881—902. doi: 10.1007/s11240-014-0664-4

18. Belik VF. (ed.) Metodika opytnogo dela v ovoshchevodstve i bakhchevodstve [Methodology of experimental work in vegetable and melon growing]. Moscow: Agropromizdat Publ.; 1992. (In Russ). 
19. Dospekhov BA. Metodika polevogo opyta [Methodology of field experience]. Moscow: Al'yans Publ.; 2011. (In Russ).

20. Druzhkin AF, Lyashenko ZD, Panina MA. Osnovy nauchnykh issledovanii v agronomii. Chast' 2. [Fundamentals of scientific research in agronomy. Part 2]. Saratov: Biometriya Publ.; 2009. (In Russ).

21. Terpelets VI, Slyusarev VN. Agrofizicheskie i agrokhimicheskie metody issledovaniya pochv [Agrophysical and agrochemical methods of soil research]. Krasnodar: KubSAU Publ.; 2016. (In Russ).

22. Federal Agency for Technical Regulation and Metrology (Rosstandart). GOST 26107-84. Metody opredeleniya obshchego azota [Methods for determination of total nitrogen]. Moscow; 1984. (In Russ).

23. Metodicheskie ukazaniya po opredeleniyu shchelochnogidrolizuemogo azota v pochve po metodu Kornfilda [Guidelines for determination of alkaline hydrolyzable nitrogen in soil by Kornfield method]. Moscow: Ministry of Agriculture of the USSR Publ.; 1985. (In Russ).

24. Federal Agency for Technical Regulation and Metrology (Rosstandart). GOST 26205-91. Pochvy. Opredelenie podvizhnykh form fosfora i kaliya po metodu Machigina v modifikatsii TSINAO [The soil. Determination of mobile forms of phosphorus and potassium according to Machigin method in the modification of TsINAO]. Moscow; 1991. (In Russ).

\section{Библиографический список}

1. Солдатенко А.В., Разин А.Ф., Пивоваров В.Ф., Шатилов М.В., Иванова М.И., Россинская O.В., Разин О.A. Овощи в системе обеспечения продовольственной безопасности России // Овощи России. 2019. № 2. С. 9-15. doi: 10.18619/2072-9146-2019-2-9-15

2. Enujeke E.C., Emuh F.N. Evaluation of some growth and yield indices of five varieties of tomato (Lycopersicon esculentum Mill.) in Asaba Area of Delta State, Nigeria // Global Journal of BioScience and Biotechnology. 2015. Vol. 4. № 1. Р. 21-26.

3. Болкунов А.И. Химический состав и пищевая ценность лука репчатого // Приоритетные направления развития современной науки молодых ученых аграриев. 2016. С. 257-301.

4. Гиш Р.А., Гикало Г.С. Овощеводство юга России. Краснодар: ЭДВИ, 2012. 632 с.

5. Итоги Всероссийской сельскохозяйственной переписи 2016 года. Земельные ресурсы и их использование / Федеральная служба гос. статистики. М.: НИЦ «Статистика России», 2018. T. 3. 307 c.

6. Калмыкова Е.В., Плескачев Ю.Н., Калмыкова О.В., Зволинский В.П. Влияние макро- и микроудобрений на качество плодов томата // Известия Нижневолжского агроуниверситетского комплекса: Наука и высшее профессиональное образование. 2019. № 1. С. 32 - 41. doi: 10.32786/2071-9485-2019-01-3

7. Тютюма Н.В., Солодовников А.П., Мухортова Т.В., Кудряшова Н.И. Определение оптимального режима орошения и уровня минерального питания гибридов томатов российской селекции в условиях севера Астраханской области // Аграрный научный журнал. 2017. № 8. С. 32-38.

8. Петров Н.Ю., Калмыкова Е.В., Убушаева С.В., Батыров В.А. Влияние агротехнических приемов на рост, развитие и продуктивность томата в условиях Нижнего Поволжья // Известия Нижневолжского агроуниверситетского комплекса: Наука и высшее профессиональное образование. 2017. № 2 (46). С. 118-125.

9. Солдатенко А.В., Пивоваров В.Ф., Разин А.Ф., Шатилов М.В., Разин О.А., Россинская О.В., Башкиров О.В. Проблемы производства конкурентной овощной продукции // Овощи России. 2019. № 1. С. 3-7. doi: 10.18619/2072-9146-2019-1-3-7

10. Курбанов С.А., Магомедова Д.С., Джамбулатова А.З. Способы орошения томатов на лугово-каштановых почвах Республики Дагестана // Научная жизнь. 2019. № 2. С. 6-13. 
11. Chauhan S.A., Patel N.B., Mehta D.R., Patel J. B., Zalaishita M., Vaja A.D. Effect of plant growth regulators on seed yield and its parameters of tomato (Lycopersicon esculentum L) // Int. J. of Agric. Sci. 2017. Vol. 9. № 8. P. 3906-3909.

12. Akand M.H., Mazed H.E.M.K., Islam M.A., Pulok M.A.I., Chowdhury M.H.N., Moonmoon J.F. Growth and yield of tomato (Lycopersicon esculentum Mill.) As influenced by different level of gibberellic acid application // Int. J. of Appl. Res. 2015. Vol. 1. № 3. P. 71-74.

13. Bairambekov Sh.B., Korneva O.G., Polyakova E.V., Gulyaeva G.V., Sokolov A.S. Agrotechnical and chemical methods of weeds control in the vegetable crop rotation link // Ecology, Environment and Conservation. Vol. 23 № 3. 2017. P. 1684-1690.

14. Соколов А.С., Байрамбеков Ш.Б., Соколова Г.Ф. Влияние обработки почвы удобрений, гербицидов на засоренность и урожайность овощных культур в севообороте // Успехи современного естествознания. 2018. № 8. С. 78-84.

15. Комаров В.Н., Киселева Н.Н., Воронщова А.И. Применение технологических приемов возделывания томата при капельном орошении // Мелиорация и проблемы восстановления сельского хозяйства России. 2013. С. 163-166.

16. Гаплаев М.Ш. Состояние и перспективы развития овощеводства в Чеченской Республике // Картофель и овощи. 2015. № 8. С. 2.

17. Gerszberg A., Katarzyna H.K., Kowalczyk T., Kononowicz A.K. Tomato (Solanum lycopersicum L.) in the service of biotechnology // Plant Cell Tiss Organ Cult. 2015. Vol. 120. № 3. P. 881-902. doi: 10.1007/s11240-014-0664-4

18. Методика опытного дела в овощеводстве и бахчеводстве / под ред. В.Ф. Белика. М.: Агропромиздат, $1992.319 \mathrm{c}$.

19. Доспехов Б.А. Методика полевого опыта. М.: Альянс, 2011. 352 с.

20. Дружкин А.Ф., Ляшенко 3.Д., Панина М.А. Основы научных исследований в агрономии. Часть 2: Биометрия. Саратов, 2009. 70 с.

21. Терпелеи В.И., Слюсарев В.Н. Агрофизические и агрохимические методы исследования почв. Краснодар: КубГАУ, 2016. 65 с.

22. ГОСТ 26107-84. Методы определения общего азота. М., 1984.

23. Методические указания по определению щелочногидролизуемого азота в почве по методу Корнфилда. М.: МСX СССР, 1985. 9 с.

24. ГОСТ 26205-91. Почвы. Определение подвижных форм фосфора и калия по методу Мачигина в модификации ЦИНАО. М., 1991.

\section{About the authors:}

Kalmykova Elena Vladimirovna - Candidate of Agricultural Sciences, Researcher, Department of Irrigation Reclamation, Laboratory for Modeling Irrigation Technologies, Russian Research Institute of Irrigated Agriculture, 9, Timiryazeva st., Volgograd, Russian Federation, 400002; e-mail: kalmykova.elena-1111@yandex.ru

Novikov Aleksey Andreevich - Candidate of Agricultural Sciences, Russian Research Institute of Irrigated Agriculture, 9, Timiryazeva st., Volgograd, Russian Federation, 400002; e-mail: novikov@riagro.ru

Petrov Nikolay Yuryevich - Doctor of Agricultural Sciences, Professor, Department of Technology for Storage and Processing of Agricultural Raw Materials and Public Food, Volgograd State Agrarian University, 26, Universitetsky Prospect, Volgograd, Russian Federation, 400002; e-mail: npetrov60@list.ru

Kalmykova Olga Vladimirovna - Candidate of Agricultural Sciences, Associate Professor, Department of Technology for Storage and Processing of Agricultural Raw Materials and Public Food, Volgograd State Agrarian University, 26, Universitetsky Prospect, Volgograd, Russian Federation, 400002; e-mail: lelya.kalm.90@mail.ru 


\section{Об авторах:}

Калмыкова Елена Владимировна - кандидат сельскохозяйственных наук, научный сотрудник отдела оросительных мелиораций, лаборатории моделирования технологий орошения, Всероссийский научно-исследовательский институт орошаемого земледелия, 400002, Российская Федерация, г. Волгоград, ул. им. Тимирязева, д. 9; e-mail: kalmykova.elena-1111@yandex.ru

Новиков Алексей Андреевич - кандидат сельскохозяйственных наук, врио директора, Всероссийский научно-исследовательский институт орошаемого земледелия, 400002, Российская Федерация, г. Волгоград, ул. им. Тимирязева, д. 9; e-mail: novikov@riagro.ru

Петров Николай Юрьевич - доктор сельскохозяйственных наук, профессор, профессор кафедры технологии хранения и переработки сельскохозяйственного сырья и общественного питания, Волгоградский государственный аграрный университет, 400002, Российская Федерация, г. Волгоград, пр. Университетский, д. 26; e-mail: npetrov60@list.ru

Калмыкова Ольга Владимировна — кандидат сельскохозяйственных наук, доцент кафедры технологии хранения и переработки сельскохозяйственного сырья и общественного питания, Волгоградский государственный аграрный университет, 400002, Российская Федерация, г. Волгоград, пр. Университетский, д. 26; e-mail: lelya.kalm.90@mail.ru 